\title{
Double gastric bubbles
}

\author{
Shinichiro OKAUCHI ${ }^{1}$ \\ Yuika SASATANI ${ }^{1}$ \\ Gen OHARA ${ }^{1}$ \\ Katsunori KAGOHASHI ${ }^{1}$ \\ Hiroaki SATOH ${ }^{1}$
}

1 Tsukuba Üniversitesi, Mito Tıp Merkezi, Göğüs Hastalıkları Bölümü, Mito, Japonya

${ }^{1}$ Division of Respiratory Medicine, Mito Medical Center, Tsukuba University, Mito, Japan
Cite this article as: Okauchi S, Sasatani Y, Ohara G, Kagohashi K, Satoh H. Double gastric bubbles. Tuberk Toraks 2019;67(2):149-50.

Yazışma Adresi (Address for Correspondence)

\section{Dr. Hiroaki SATOH}

Division of Respiratory Medicine, Mito Medical Center, Tsukuba University, MITO - JAPONYA

e-mail: hirosato0809@yahoo.jp

CCopyright 2019 by Tuberculosis and Thorax. Available on-line at www.tuberktoraks.org.com
To the Editor,

A 70 year old man was referred to our hospital due to cough, sputum, and fever. In the chest image, there was infiltrative opacity in the left lower lobe of the lung with massive pleural fluid. The patient was diagnosed as having pleuropneumonia, which was successfully treated with antibiotics. Two weeks after the initiation of the therapy with improved symptoms and inflammatory response, a chest radiograph showed "two gastric bubbles" at the site of "a gastric bubble" would be anatomically existed (Figure 1A). In chest computed tomography (CT) scan, thin-wall cyst with air-fluid level was existed in the lower lobe of the left lung. Adjacent to the bullae there was no consolidation but slight increased density of left lower lung, which suggested a change after inflammation of the lobe (Figure 1B).

It was not necessarily clear whether the cavitary lesion in the left lower lobe was infected bulla with air-fluid level or lung abscess. In general, the wall of lung abscess is thick and often has consolidation adjacent to it (1). On the other hand, the wall of bullae is thin and often does not necessarily accompany consolidation in the surroundings (2). In the present patient, the existence of bullae was not confirmed due to the presence of pleuropneumonia in the plain chest photograph taken at the time of admission. Based on the presence of thin wall and the absence of consolidation surrounding the cavitary lesion, the cavitary lesion was evaluated as an infected bulla rather than a lung abscess. The famous "double bubble sign" signature is observed by the obstruction of the upper gastrointestinal 


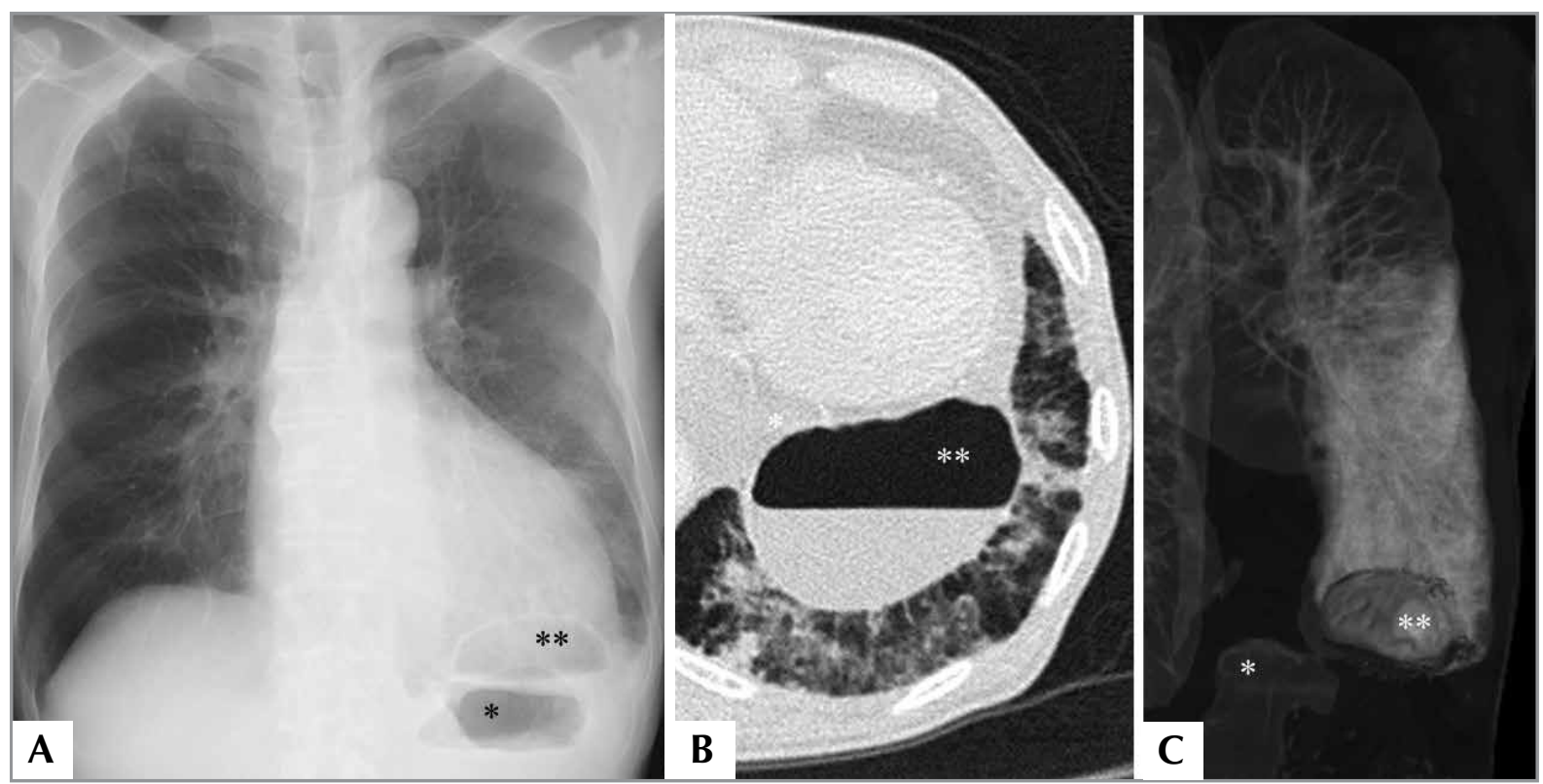

Figure 1. In a chest radiograph taken two weeks after initiation of antibiotic, there were "two" gastric bubbles (A). In a chest computed tomography scan, thin-wall bullae with air-fluid level was existed in the lower lobe of the left lung (B). Three-dimensional computer graphic analysis of images revealed that the "gastric bubble" located on the caudal side was due to bullae in the left lower lobe of the lung (C).

*: gastric bubble, ${ }^{* *}$ : thin-wall cyst in the lower lobe of the left lung.

tract (3). As observed in the present case, it is interesting that similar findings can be exhibited by the lesion of the lower lobe of the left lung. In our patient, the "gastric bubble" located on the caudal side was confirmed due to thin-wall bullae with air-fluid level in the left lower lobe of the lung (Figure 1C). An infected bulla of the left lower lobe of the lung may exhibit abnormality similar to gastric bubble when accompanied by air-fluid level. Regarding the lesion adjacent to the diaphragm in axial section of CT scan, there are some cases in which it is difficult to judge whether the lesion exist in the thorax or in the abdominal cavity. If questions remain in the interpretation of CT images, three-dimensional computer graphic analysis of images may be useful (4).

\section{REFERENCES}

1. Schiza S, Siafakas NM. Clinical presentation and management of empyema, lung abscess and pleural effusion. Curr Opin Pulm Med 2006;12:205-11.

2. Satoh H, Suyama T, Yamashita YT, Ohtsuka M, Sekizawa K. Spontaneous regression of multiple emphysematous bullae. Can Respir J 1999;6:458-60.

3. Shen YC, Lin YS. Double-bubble sign in an adult patient. Gastroenterology 2017;153:1191-2.

4. Ikeda N, Yoshimura A, Hagiwara M, Akata S, Saji H. Three dimensional computed tomography lung modeling is useful in simulation and navigation of lung cancer surgery. Ann Thorac Cardiovasc Surg 2013;19:1-5. 